\title{
The language of radioactivity
}

Hans-Georg Menzel walks us through the complex set of units characterizing radioactivity and ionizing radiation.

T he story of ionizing radiation and radioactivity, and their units, has its origins in the late 1890s, with W. C. Röntgen's discovery of X-rays (1895), H. Becquerel's observation of uranium salts spontaneously emitting similar radiation (1896) and M. Skłodowska-Curie’s announcement of the discovery of polonium and radium (1898). (Interestingly, all these findings led to early Nobel Prizes in Physics).

Röntgen's discovery instantly found great attention worldwide. As gas discharge tubes were readily available in many laboratories, applications of X-rays were investigated immediately - the picture shows an X-ray image of fish (Zanclus cornutus and Acanthurus nigros) recorded in 1896. Uses of $\mathrm{X}$-rays for medical diagnostics and therapy were the focus for several decades. Since damage to skin and tissue was observed when exposed to X-ray radiation, there was a clear need for a reliable method for its measurement and control. It may now appear curious, but evaluating the exposure leading to skin reddening (erythema) was a common method of 'dosage control' in radiation therapy for almost two decades.

It was more than 30 years after Röntgen's discovery that an internationally recognized unit for X-ray exposure was established. In 1928, the Second International Congress on Radiology in Stockholm ${ }^{1}$ adopted the unit röntgen $(\mathrm{R})$. Based on the notion that X-rays cause ionization in air and that the ensuing electrical charge can be measured, the röntgen was defined in terms of the electric charge freed by X-rays in a specified volume of air divided by the mass of that air; specifically, $1 \mathrm{R}$ corresponds to one electrostatic unit of conductivity produced by $\mathrm{X}$-rays in one cubic centimetre of atmospheric air at $0{ }^{\circ} \mathrm{C}$ and $76 \mathrm{~cm} \mathrm{Hg}$. This definition is tied to a particular type of measurement, namely the use of (parallel plate) ionization chambers, and is limited to $\mathrm{X}$ - and $\gamma$-rays.

In 1953, the International Commission on Radiation Units and Measurements introduced the quantity 'absorbed dose' as the amount of energy imparted to matter by any ionizing particles per unit mass of irradiated matter at the place of interest. The unit used for absorbed dose was the

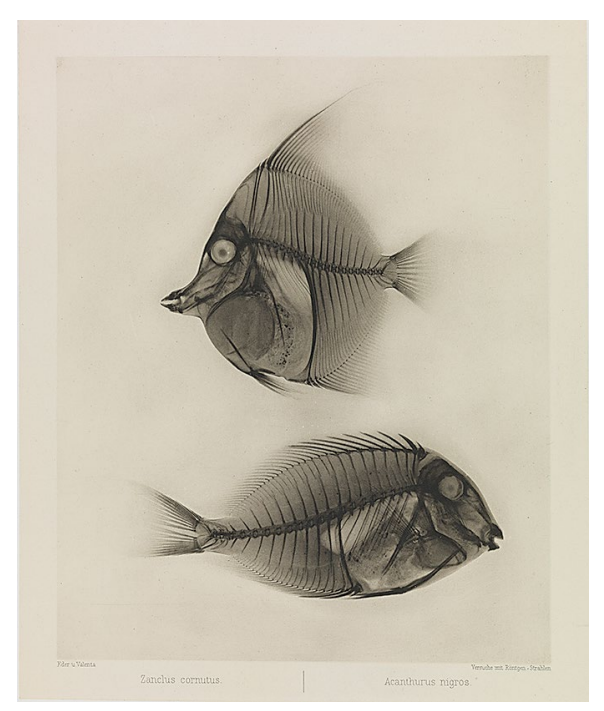

Credit: Kodak Collection/National Museum of Science \& Media/Science \& Society Picture Library - all rights reserved

$\operatorname{rad}\left(1 \mathrm{rad}=0.01 \mathrm{~J} \mathrm{~kg}^{-1} ;\right.$ ref. $\left.^{2}\right)$. Energy 'left behind' in irradiated matter, in particular biological matter and human tissue, was considered to be closely related to the effects induced by ionizing radiation. The quantity absorbed dose is applicable to any kind of ionizing radiation and any kind of matter. In 1975, the SI unit J kg${ }^{-1}$ was adopted for absorbed dose, with gray (Gy) the special name for it. Absorbed dose is a metrologically sound quantity for which primary standards for a few materials exist. It is the fundamental dosimetric quantity for all applications of ionizing radiation, including radiation therapy and radiation protection ${ }^{3}$.

The effect of ionizing radiation to induce given biological effects, however, depends not only on the absorbed dose, but also on the type and energy of the ionizing radiation - as well as on temporal aspects. To account for these differences in radiation protection, the quantity 'dose equivalent' was introduced as the product of absorbed dose and an empirical quality factor $Q$. The recommended numerical values of $Q$ are based on radiobiological results. $Q$ is a dimensionless quantity, so the
SI unit of dose equivalent is $\mathrm{J} \mathrm{kg}^{-1}$, for which the International Committee for Weights and Measures introduced the special unit sievert (Sv). Note that the sievert is not a purely physical unit; it is used for a physical quantity weighted by a biological response function. (It is similar to the candela, the base unit of luminous intensity, which is weighted by a luminosity function as a model of the sensitivity of the human eye to different wavelengths.) In radiation therapy with protons and ${ }^{12} \mathrm{C}$ ions, empirical weighting factors for absorbed dose are also applied, based on radiobiology and clinical experience 4 .

Back to radium. Soon after its discovery, the element was used for medical therapeutic purposes. It also led to a unit for the quantity now called 'activity'. In 1910, E. Rutherford wrote in Nature that the radium standards committee "suggested that the name Curie $[\mathrm{C}]$ be used as a new unit to express the quantity or mass of radium emanation [radon] in equilibrium with one gram of radium (element)." The definition was based on the rate of decay of atoms within one gram of radium, which is $3.7 \times 10^{10}$ per second. In 1975 the General Conference on Weights and Measures introduced the SI unit $\mathrm{s}^{-1}$ for activity, with becquerel $(\mathrm{Bq})$ its special name. Therefore, $1 \mathrm{C}=3.7 \times 10^{10} \mathrm{~Bq}=$ $37 \mathrm{GBq}$ or $1 \mathrm{~Bq} \approx 27 \mathrm{pC}$. The very large difference in the numerical values of the two units is due to the choice of $1 \mathrm{~g}$ of radium as the reference mass in 1910, which was a huge amount of radium at that time.

\section{Hans-Georg Menzel}

International Commission on Radiation Units and Measurements (ICRU), Bethesda, MD, USA.

e-mail:hans.menzel@outlook.com

Published online: 4 July 2018

https://doi.org/10.1038/s41567-018-0207-8

\footnotetext{
References

1. Soiland, A. Radiology 10, 443 (1928).

2. Taylor, L. S. Health Phys. 1, 306-314 (1958).

3. Report 85a: Fundamental Quantities and Units for Ionizing Radiation (ICRU, 2011)

4. Bentzen, S. M. et al. Radiother. Oncol. 105, 266-268 (2012).

5. Rutherford, E. Nature 84, 430-431 (1910).
}

$\mathrm{m} e \mathrm{~A} \mathrm{~s} R \mathrm{E}_{\mathrm{h}}$

\section{$\mu_{0}$}

\section{$\varepsilon_{0}$}

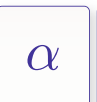

$\sigma$ 